\title{
Local Head and Neck Cooling Leads to Hypothermia in Healthy Volunteers
}

\author{
Bernd Kallmünzer Alexander Beck Stefan Schwab Rainer Kollmar \\ Department of Neurology, University Hospital Erlangen, Friedrich Alexander University Erlangen-Nürnberg, \\ Erlangen, Germany
}

Key Words

Hypothermia $\cdot$ Cooling cap $\cdot$ Cooling $\cdot$ Stroke

\begin{abstract}
Background: Prehospital cooling of acute stroke patients would be ideal when associated with minor or no side effects. Therefore, we evaluated a cooling cap for the surface of head and cervical regions in awake volunteers. Methods: 10 healthy volunteers were treated by external cooling for 190 min using a gel-based cooling device. Vital signs, rectal temperature, tympanic temperature, the extent of shivering and individual perception of frostiness and discomfort were measured. Results: All participants (median age 35 years) successfully completed the treatment and experienced only mild to moderate discomfort. No serious adverse events and no shivering were noticed. There was a significant drop in the tympanic temperature to $34.68^{\circ} \mathrm{C}$ (difference from baseline: $\left.1.7^{\circ} \mathrm{C}, 95 \% \mathrm{Cl}: 0.61-2.7^{\circ} \mathrm{C}, \mathrm{p}=0.001\right)$, in the rectal temperature to $36.65^{\circ} \mathrm{C}$ (difference from baseline: $0.65^{\circ} \mathrm{C}, 95 \%$ $\mathrm{Cl}: 0.06-1.2^{\circ} \mathrm{C}, \mathrm{p}=0.019$ ) and in the heart rate (difference from baseline: 15 beats $/ \mathrm{min}, 95 \% \mathrm{Cl}: 0.63-30$ beats $/ \mathrm{min}, \mathrm{p}=$ 0.035). Conclusion: Treatment with the cooling device was well tolerated by all participants. The technique had measurable effects on core body temperature (rectal) and tympanic temperature (may reflect temperature at the external ear and skin rather than intracranial). It can be considered as a simple therapeutic approach to patients with suspected stroke in the prehospital setting.
\end{abstract}

Copyright $\odot 2011$ S. Karger AG, Basel

\section{Introduction}

Therapeutic hypothermia is a promising neuroprotective strategy for awake patients with acute ischemic stroke [1]. Animal studies have suggested that the benefit of cooling is larger the earlier this therapy is started [2]. For this reason, cooling may be more effective when initiated already before the patient arrives at the hospital. While the rapid infusion of cold saline and devices for external cooling have been tested successfully in patients after cardiac arrest [3], data on prehospital cooling in suspected stroke are lacking. In contrast to survivors of cardiac arrest, the majority of acute stroke patients is awake and nonsedated. Furthermore, the diagnosis can be misleading in the initial situation and an acceptable benefit-risk ratio must be considered for the cooling method. Up to date, data on the safety of the rapid-saline-infusion method are preliminary [4] and concerns arise from serious fluid overload with respiratory deterioration [5]. In this study, we tested the feasibility, safety and temperature effects of a commercially available cooling cap, covering the surface of the head and neck in healthy volunteers.

\section{Methods}

This study was approved by the local ethics committee of the Medical Faculty, University of Erlangen-Nuremberg. The head and neck cooling device (HVM Medical, Rothenburg, Germany) contains free-floating cooling gel with a central portion, covering the head with the exception of the face, and 3 flaps, 1 for the dor-

\section{KARGER}

Fax +41613061234 E-Mail karger@karger.ch www.karger.com
Bernd Kallmünzer, MD

Department of Neurology, University Hospital Erlangen

Friedrich Alexander University Erlangen-Nürnberg

Schwabachanlage 6, DE-91054 Erlangen (Germany)

Tel. +4991318534563, E-Mail bernd.kallmuenzer@uk-erlangen.de 
sal cervical region and 2 for both carotid triangles (fig. 1). Prior to its use, the device is kept at $4^{\circ} \mathrm{C}$. Inclusion criteria for the present study were an unremarkable medical history with absence of any active disease, fever, infection or any medication within 4 weeks prior to participation. After obtaining written informed consent, 10 healthy volunteers lied down on an examination couch and were connected to a multimodal monitoring system (Infinity Gamma-Series, Dräger Medical, USA), including continuous ECG, blood pressure and pulse oximetry. A temperature probe (Temprecise, Arizant Healthcare, Inc., USA) was inserted into the rectum. Tympanic temperature was measured with an electronic thermometer (Genius 2 tympanic thermometer, Tyco Healthcare Group, Mansfield, USA). The volunteers rated the perception of frostiness and overall discomfort on a visual analogue scale ranging from 0 (not any) to 10 (maximum). Shivering was quantified from 0 to 3 as described previously [6]. Environmental temperature was set constantly to $23^{\circ} \mathrm{C}$ and the volunteer's body was covered with a blanket to avoid heat loss from the trunk and extremities. An initial resting phase of $20 \mathrm{~min}$ prior to cooling allowed adaption to the local environment. After treatment completion, the measurements were continued for another $30 \mathrm{~min}$. A standardized questionnaire was used to assess any adverse events within 24 h by telephone.

Data were processed using the PASW Statistics 18 (SPSS Inc., USA) software package. Normality of distribution was tested using the Shapiro-Wilk and Kolmogorov-Smirnov tests. Data are summarized as means and standard deviations or medians and interquartile ranges (IQR), if they were not distributed normally. Physiologic data were tested for significant differences by repeated-measures ANOVA. The level of significance was set a priori at $\mathrm{p}=0.05$. If applicable, the Greenhouse-Geisser correction was used.

\section{Results}

Four women and 6 men (median age $=35$ years, $\mathrm{IQR}=28-42$ years) with a median body weight of $80 \mathrm{~kg}$ $(\mathrm{IQR}=67.3-95.3 \mathrm{~kg})$ and a body mass index of 25.3 (IQR $=23.3-30.1)$ participated in the study.

No serious adverse events, no cardiac arrhythmias, no blood pressure crises or intolerable discomfort occurred during the treatment. Moreover, no shivering was noticed. For the perception of frostiness, a maximum score of 4.5 (IQR $=2-6)$ was reached on the visual analogue scale after $10 \mathrm{~min}(\mathrm{IQR}=10-12.5 \mathrm{~min})$. The maximum value for discomfort was $3(\mathrm{IQR}=2-4)$ after $50 \mathrm{~min}$. Four test persons complained of moderate headache or pain in the neck during treatment. In 1 case, moderate occipital headache started $3 \mathrm{~h}$ after treatment completion. All symptoms had resolved completely during follow-up. No other adverse events occurred.

The mean rectal temperature at baseline was $37.3 \pm$ $0.3^{\circ} \mathrm{C}$, while 3 participants presented with elevated core body temperature of 37.6 or $37.7^{\circ} \mathrm{C}$ prior to treatment.

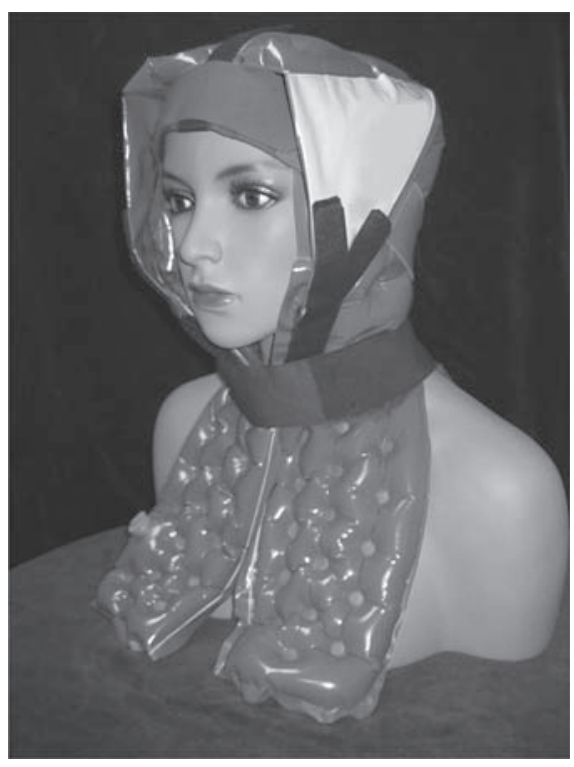

Fig. 1. The gel-based cooling device for head and neck consists of a central portion and 3 flaps, 1 for the dorsal cervical region and 2 for both carotid triangles.

Under therapy, a drop in rectal temperature occurred (fig. 2) and the mean difference from baseline measured $0.65^{\circ} \mathrm{C}\left(95 \% \mathrm{CI}=0.064-1.2^{\circ} \mathrm{C}, \mathrm{p}=0.019\right.$; fig. 3$)$ after 60 $\pm 54 \mathrm{~min}$. The mean tympanic temperature at baseline was $36.4 \pm 0.4^{\circ} \mathrm{C}$. The lowest values were reached after $36 \pm 12 \mathrm{~min}$ and the mean difference from baseline measured $1.7^{\circ} \mathrm{C}\left(95 \% \mathrm{CI}=0.61-2.7^{\circ} \mathrm{C}, \mathrm{p}=0.001\right)$. In all participants, the tympanic temperature dropped below $35.7^{\circ} \mathrm{C}$, but never exceeded $33.3^{\circ} \mathrm{C}$.

An early drop in heart rate with consecutive slow reincrease occurred during cooling. The minimum was reached after $49 \pm 37 \mathrm{~min}$ and the mean difference from baseline measured 15 beats $/ \mathrm{min}(95 \% \mathrm{CI}=0.63-30$ beats $/$ min, $\mathrm{p}=0.036)$. Arterial blood pressure measurements $(\mathrm{F}=0.45$, d.f. $=11, \mathrm{p}=0.926)$ and pulse oximetry $(\mathrm{F}=$ 0.332 , d.f. $=10, p=0.97)$ revealed no significant changes.

\section{Discussion}

Treatment by local cooling on the head and neck led to a drop in tympanic and rectal temperature and the procedure was well tolerated by all participants. Neither serious adverse events nor shivering occurred.

There is a strong association between initial core body temperature and the clinical outcome of patients with cerebral injuries [7]. In acute ischemic stroke, with each $1^{\circ} \mathrm{C}$ 

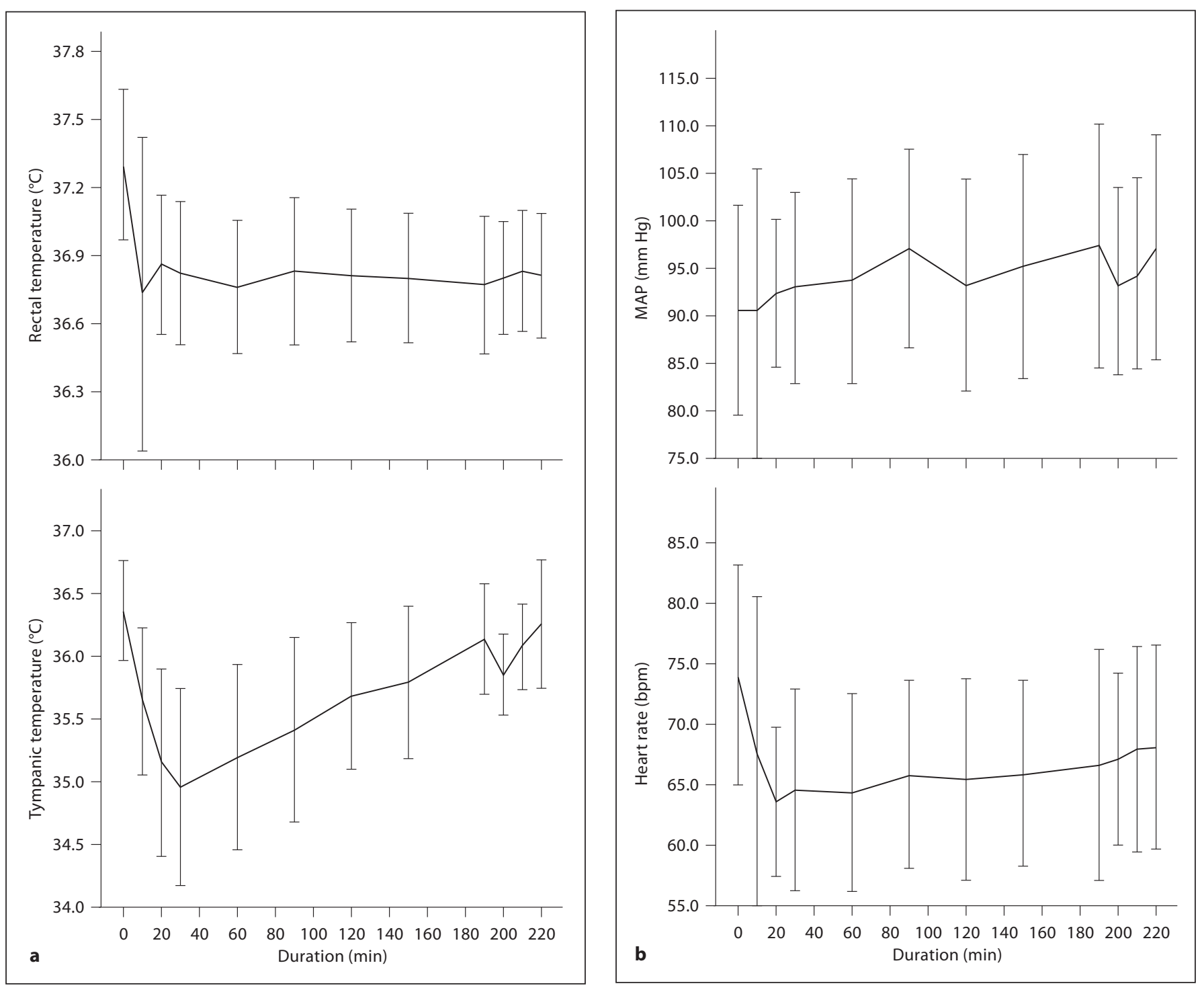

Fig. 2. Time course of tympanic and rectal temperature. (a) Heart rate and mean arterial blood pressure (b) during the treatment phase (0-190 min) and the post-treatment phase (starting at $190 \mathrm{~min})$. Error bars indicate standard deviations. MAP $=$ Mean arterial blood pressure.

increase in temperature on admission, the relative risk for death or severe neurologic deficits at discharge rises by the factor of 2.2 [8]. In the present study, a drop in the core body temperature by $0.65^{\circ} \mathrm{C}$ was observed during treatment in healthy volunteers. Given the strong association mentioned before, this rather small effect should still be of clinical relevance. In addition, the applied intensity of cooling was tolerated well by all participants. Enforcing a larger decrease of the core body temperature might cause serious side effects and shivering, leading to an inappropriate risk profile of this method. However, the cooling cap is developed for the use outside the hospital setting in anticipation of more invasive cooling techniques, e.g. endovascular catheters, under the controlled conditions of an intensive care unit.

At present, there is no sufficient evidence for the assumption that surface cooling at the head could lower the intracranial temperature to a greater extent than the core body temperature, and results from clinical studies are conflicting $[9,10]$. However, it was suggested that head caps reduce cerebral temperature mainly in superficial, cortical brain regions, while cooling with neck bands 


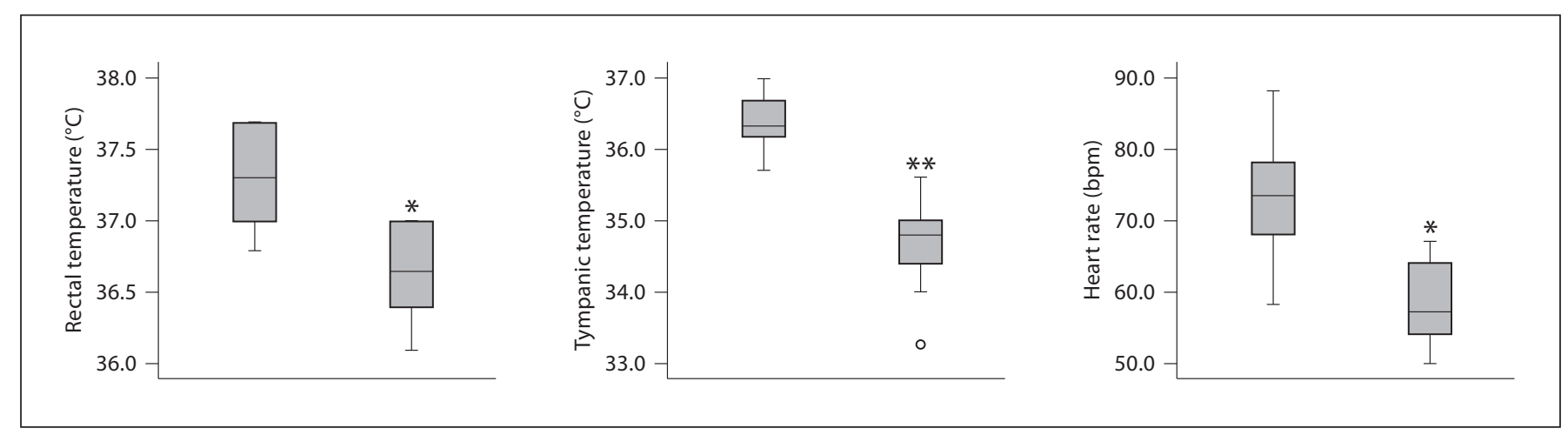

Fig. 3. Effect of surface cooling of head and neck on rectal temperature, tympanic temperature and heart rate. Data reflect mean lowest values during treatment compared to baseline. ${ }^{*} \mathrm{p}=0.05 ;{ }^{*} \mathrm{p}=0.001$.

could lead to hypothermia also in the deep brain [11], probably delivered through the cranial vessels. Whether the cervical flaps of the cooling devices are capable of mediating similar effects remains hypothetical and requires confirmation by future investigations.

Tympanic and rectal temperature measurements show acceptable agreement in normothermic stroke patients [12]. In the setting of the present study, local cooling is performed with close contact to the external ear. Therefore, tympanic readings may be artificially low and should be interpreted as a surrogate of a local cooling effect at superficial regions, including skin and the external ear. This probably does not reflect intracranial temperature.
Exposure of the forehead to a cold stimulus had previously been reported to trigger central vagal activation with reactive bradycardia [13] and an increase in cerebral blood flow [14] in humans. Bradycardia was also noted as a consequence of surface cooling in the present study. Further research is necessary to investigate autonomic changes during treatment with the cooling device.

In conclusion, the investigated method of surface cooling for head and neck is feasible and effective in conscious volunteers. It can be considered as a method for preclinical induction of hypothermia.

\section{References}

1 Kollmar R, Schwab S: Hypothermia in focal ischemia: implications of experiments and experience. J Neurotrauma 2009;26:377386.

2 van der Worp HB, Sena ES, Donnan GA, Howells DW, Macleod MR: Hypothermia in animal models of acute ischaemic stroke: a systematic review and meta-analysis. Brain 2007;130:3063-3074.

3 Cabanas JG, Brice JH, De Maio VJ, Myers B, Hinchey PR: Field-induced therapeutic hypothermia for neuroprotection after out-of hospital cardiac arrest: a systematic review of the literature. J Emerg Med 2011;40:400409.

4 Kollmar R, Schellinger PD, Steigleder T, Kohrmann M, Schwab S: Ice-cold saline for the induction of mild hypothermia in patients with acute ischemic stroke: a pilot study. Stroke 2009;40:1907-1909.

5 Jacobshagen C, Pax A, Unsold BW, Seidler T, Schmidt-Schweda S, Hasenfuss G, Maier LS: Effects of large volume, ice-cold intravenous fluid infusion on respiratory function in cardiac arrest survivors. Resuscitation 2009;80: 1223-1228.

6 Guluma KZ, Hemmen TM, Olsen SE, Rapp KS, Lyden PD: A trial of therapeutic hypothermia via endovascular approach in awake patients with acute ischemic stroke: methodology. Acad Emerg Med 2006;13:820-827.

7 Greer DM, Funk SE, Reaven NL, Ouzounelli M, Uman GC: Impact of fever on outcome in patients with stroke and neurologic injury: a comprehensive meta-analysis. Stroke 2008; 39:3029-3035.

8 Reith J, Jorgensen HS, Pedersen PM, Nakayama H, Raaschou HO, Jeppesen LL, Olsen TS: Body temperature in acute stroke: relation to stroke severity, infarct size, mortality, and outcome. Lancet 1996;347:422425.

9 Mellergard P: Changes in human intracerebral temperature in response to different methods of brain cooling. Neurosurgery 1992;31:671-677.
10 Wang H, Olivero W, Lanzino G, Elkins W, Rose J, Honings D, Rodde M, Burnham J, Wang D: Rapid and selective cerebral hypothermia achieved using a cooling helmet. J Neurosurg 2004;100:272-277.

11 Keller E, Mudra R, Gugl C, Seule M, Mink S, Frohlich J: Theoretical evaluations of therapeutic systemic and local cerebral hypothermia. J Neurosci Methods 2009;178:345-349.

12 Christensen H, Boysen G: Acceptable agreement between tympanic and rectal temperature in acute stroke patients. Int J Clin Pract 2002;56:82-84.

13 Stemper B, Hilz MJ, Rauhut U, Neundorfer B: Evaluation of cold face test bradycardia by means of spectral analysis. Clin Auton Res 2002;12:78-83.

14 Brown CM, Sanya EO, Hilz MJ: Effect of cold face stimulation on cerebral blood flow in humans. Brain Res Bull 2003;61:81-86. 